\title{
KAJIAN KEBUTUHAN TENAGA DOKTER UMUM DENGAN MENGGUNAKAN METODE WORKLOAD INDICATOR STAFF NEED (WISN) DI POLI UMUM DAN UNIT GAWAT DARURAT (UGD) RSUD KABUPATEN BUTON UTARA
}

\section{Study of Availability of Public Doctors By Using Workload Indicator Staff Need (WISN) In Public Police And Emergency Units General Hospital North Buton District}

\author{
Muhammad Ikhsan Akbar, Leniarti Ali, Ratnawati \\ Program Studi Sarjana Kesehatan Masyarakat \\ Universitas Mandala Waluya \\ (muhikhsanakbar24@gmail.com, 081354636426)
}

\begin{abstract}
ABSTRAK
Ketersediaan sumber daya manusia kesehatan di rumah sakit harus menjadi perhatian, utamanya pada perencanaan kebutuhan Sumber daya manusia secara tepat sesuai dengan fungsi pelayanan setiap unit, bagian, dan instalasi rumah sakit. Penelitian ini bertujuan untuk mengetahui kebutuhan dokter umum di Rumah Sakit Umum Daerah Kabupaten Buton Utara. Penelitian ini menggunakan pendekatan desikriptif dengan menggunakan Metode Perhitungan Workload Indicator Staff Need (WISN). Instrumen pengumpulan data yang digunakan yaitu lembar observasi. Teknik analisis data menggunakan analisis WISN. Hasil penelitian ini menunjukan bahwa waktu kerja tersedia bagi Dokter Umum adalah 244 hari kerja tersedia atau 1500 waktu kerja tersedia dalam satu tahun. Dengan kegiatan dan standar beban kerja Dokter Umum di poli umum sebesar 18000 dan di Unit Gawat Darurat sebesar 45000. Sementara itu standar kelonggaran dokter umum sebesar 0,22. Dengan kuantitas kegiatan pokok pada poli umum sebesar 130 dan Unit Gawat Darurat sebesar 366 maka kebutuhan Dokter Umum di Rumah Sakit Umum Buton Utara sebesar 1,6 atau dibulatkan menjadi 2. Penelitian ini menyimpulkan bahwa Rumah Sakit Umum Daerah Buton Utara membutuhkan tambahan tenaga Dokter Umum untuk memenuhi pelayanan kesehatan yang lebih paripurna kepada pasien RSUD Buton Utara.
\end{abstract}

Kata Kunci: Kebutuhan, WISN, dokter umum, rumah sakit umum daerah buton utara

\section{ABSTRACT}

The availability of human resources in the Hospital must be a concern, especially in planning human resource needs appropriately in accordance with the service functions of each unit, section, and installation of the Hospital. This study aims to determine the needs of general practitioners in North Buton District General Hospital. This study uses a descriptive approach using the Calculation Method Workload Indicator Staff Need (WISN). Data collection instruments used were observation sheets. Data analysis techniques using WISN analysis. The results of this study indicate that working time available for general practitioners is 244 working days available or 1500 working hours available in one year. With the activities and workload standards of general practitioners in general poly at 18000 and in the Emergency Unit at 45000. Meanwhile the general practitioner allowance standard is 0,22 . With the total number of primary polyclinic activities at 130 and the emergency department at 366, the need for general practitioners at North Buton General Hospital is 1.6 or rounded to 2. This study concludes that the North Buton Regional General Hospital requires additional general practitioners to provide more complete health services to North Buton District Hospital patients.

Keywords: Needs, WISN, general physician, north buton district general hospital 


\section{PENDAHULUAN}

Rumah sakit adalah institusi pelayanan kesehatan yang turut berperan penyelenggaraan pembangunan kesehatan. Salah satu indikator keberhasilan rumah sakit yang efektif dan efisien adalah tersedianya SDM yang cukup dengan kualitas yang tinggi, profesional sesuai dengan fungsi dan tugas setiap personil. Ketersediaan SDM di rumah sakit harus menjadi perhatian. Utamanya pada perencanaan kebutuhan SDM secara tepat sesuai dengan fungsi pelayanan setiap unit, bagian, dan instalasi rumah sakit. The World Health Organization (WHO) menyebutkan pada tahun 2006, Indonesia termasuk salah satu dari 57 negara yang krisis tenaga kesehatan, baik jumlahnya yang kurang maupun distribusinya. ${ }^{1}$ Menurut data Kementerian Kesehatan, hingga akhir 2018 terdapat 134.459 dokter umum di seluruh Indonesia. Dengan jumlah penduduk mencapai 265 juta jiwa, maka setiap dokter rata-rata melayani sekitar 1.900 penduduk. Lebih dari separuh jumlah dokter di Indonesia praktek di Pulau Jawa. jumlahnya mencapai 78.837 dokter umum. ${ }^{2}$

Profil Kesehatan Sulawesi Tenggara tahun 2018 menyebutkan bahwa Dokter Umum di Sulawesi Tenggara terbatas yaitu sebanyak 435 dokter umum dengan rasio 42,75 dokter umum per 100.000 penduduk. Distribusi Dokter Umum terbanyak di Kota Kendari yaitu 5,38 per 100.000 penduduk. sedangkan untuk Kabupaten Buton Utara sebesar 2.86 per 100.000 penduduk. ${ }^{3}$ Berdasarkan rasio dokter umum yaitu 40 per
100.000 penduduk maka diketahui bahwa 1 dokter melayani 250 penduduk sehingga untuk Kabupaten Buton Utara dengan penduduk sebanyak 63.070 maka Dokter Umum yang dibutuhkan sebanyak 252 dokter. Profil RSUD Kabupaten Buton Utara tahun 2018 menyebutkan jumlah tenaga medis per Desember 2019 terbagi atas 3 Dokter Umum, 1 Dokter Gigi, 1 Spesialis Dalam, 1 Spesialis Kesehatan Anak, 1 Spesialis Bedah, 1 Spesialis Kandungan, 1 Spesialis Anastesi. ${ }^{4}$

Menurut Keputusan Menteri Kesehatan No. 81 Tahun 2004 tentang Pedoman Penyusunan Perencanaan SDM Kesehatan di Tingkat Provinsi, Kabupaten/ Kota serta Rumah Sakit, disebutkan bahwa salah satu metode dalam perencanaan kebutuhan tenaga kesehatan di institusi adalah dengan menghitung beban kerja. Adapun perhitungan beban kerja ini dapat dilakukan dengan Metode Workload Indicator Staff Need (WISN) didasarkan pada beban kerja personel. Kelebihan daripada metode ini adalah mudah dioperasikan, mudah digunakan, secara teknis mudah diterapkan, komprehensif dan realistis. ${ }^{5}$

Rumah Sakit Umum Daerah Kabupaten Buton Utara merupakan Rumah Sakit Tipe D yang mampu menampung pelayanan rujukan dari Puskesmas dengan jumlah kunjungan sebanyak 904 kunjungan. Survey awal yang dilakukan di Rumah Sakit Umum Daerah Kabupaten Buton Utara Perencanaan tenaga kesehatan khususnya Dokter Umum di Rumah sakit ini masih belum menggunakan metode yang dengan pasti dapat menghitung kebutuhan tenaga kesehatan. 
Berdasarkan latar belakang di atas peneliti tertarik untuk melakukan penelitian dengan judul Kajian Kebutuhan Tenaga Dokter Umum Dengan Menggunakan Metode Workload Indicator Staff Need (WISN) Di RSUD Kabupaten Buton Utara.

\section{BAHAN DAN METODE}

Penelitian ini menggunakan pendekatan desikriptif menggunakan metode Perhitungan Workload Indicator Staff Need (WISN). Sampel dalam penelitian ini adalah 3 dokter umum di RSUD Buton Utara. Data primer diperoleh dari pengamatan (observasi) secara langsung pada kegiatan atau aktivitas yang dilakukan oleh dokter umum. Instrumen penelitian menggunakan lembar pengamatan dan handphone. Tehnik analisis data menggunakan analisis deskriptif.

\section{HASIL}

Langkah pertama yaitu dengan menetapkan waktu kerja tersedia. Hasil pada Tabel 1 menunjukan bahwa hari kerja tersedia bagi Dokter Umum di Poli Umum dan UGD Rumah Sakit Umum Daerah Kabupaten Buton Utara adalah 244 hari kerja tersedia atau 1500 waktu kerja tersedia dalam satu tahun.

Langkah kedua yaitu menetapkan kegiatan pokok Dokter Umum Rumah Sakit Umum Daerah Kabupaten Buton Utara. Hasil pada Tabel 2 kegiatan pokok Dokter Umum di ruang Poli Umum adalah melakukan anamnesa penyakit, melakukan pemeriksaan fisik dan atau pemeriksaan penunjang (rujukan) dan melakukan penulisan resep dan memberikan penyuluhan. Rata -rata waktu digunakan

\section{Tabel 1. Waktu Kerja Tersedia Dokter Umum di Poli Umum dan UGD RSUD Buton Utara}

\begin{tabular}{|c|c|c|c|}
\hline Kode & Faktor & Jumlah & Keterangan \\
\hline A & $\begin{array}{l}\text { Hari Kerja } \\
(6 \times 52 \\
\text { minggu })\end{array}$ & 312 & Hari/Tahun \\
\hline B & $\begin{array}{l}\text { Cuti } \\
\text { Tahunan }\end{array}$ & 12 & Hari/Tahun \\
\hline $\mathrm{C}$ & $\begin{array}{l}\text { Pendidikan } \\
\text { dan } \\
\text { Pelatihan } \\
\end{array}$ & 0 & Hari/Tahun \\
\hline $\mathrm{D}$ & $\begin{array}{l}\text { Hari Libur } \\
\text { Nasional }\end{array}$ & 20 & Hari/Tahun \\
\hline $\mathrm{E}$ & $\begin{array}{l}\text { Rata-rata } \\
\text { Ketidakhadi } \\
\text { ran Kerja }\end{array}$ & 30 & Hari/Tahun \\
\hline $\mathrm{F}$ & Waktu Kerja & 6 & Jam/Hari \\
\hline \multicolumn{2}{|c|}{$\begin{array}{c}\text { Total Hari Kerja }= \\
(A-(B+C+D+E))\end{array}$} & 244 & Hari/Tahun \\
\hline \multicolumn{2}{|c|}{$\begin{array}{c}\text { Waktu Kerja } \\
\text { Tersedia = } \\
(\mathrm{A}-(\mathrm{B}+\mathrm{C}+\mathrm{D}+\mathrm{E})) \mathrm{x}\end{array}$} & 1.500 & Jam/Tahun \\
\hline \multicolumn{2}{|c|}{$\begin{array}{c}\text { Total Waktu Kerja } \\
\text { Tersedia }\end{array}$} & 90.000 & Menit/Tahun \\
\hline
\end{tabular}

adalah 5 menit. Pada Tabel 2 kegiatan pokok Dokter Umum di ruang UGD adalah anamnesa 3 menit, pemeriksaan fisik 5 menit, melakukan tindakan kegawatdaruratan 10 menit, membuat catatan medis dan menulis resep 2 menit, konsultasi 2 menit, melakukan rujukan 2 menit.

Langkah ketiga yaitu menentukan standar beban kerja. Hasil pada Tabel 3 menunjukan bahwa Dokter Umum di Poli Umum memiliki standar beban kerja per tahun sebesar 18000 pemeriksaan pasien disemua kegiatan pokok. Sedangkan di ruang UGD standar beban kerja tertinggi sebesar 45000 pada kegiatan konsultasi dan melakukan rujukan. 
Tabel 2. Kegiatan Pokok Dokter Umum Rumah Sakit Umum Daerah Kabupaten Buton Utara

\begin{tabular}{|c|c|c|c|}
\hline Unit Kerja & Kategori SDM & Kegiatan Pokok & Waktu \\
\hline \multirow{3}{*}{ Poli Klinik } & \multirow{3}{*}{ Dokter Umum } & Melakukan anamnesa penyakit & 5 menit \\
\hline & & $\begin{array}{l}\text { Melakukan pemeriksaan fisik dan atau } \\
\text { pemeriksaan penunjang (rujukan). }\end{array}$ & 5 menit \\
\hline & & $\begin{array}{l}\text { Melakukan penulisan resep dan memberikan } \\
\text { penyuluhan }\end{array}$ & 5 menit \\
\hline \multirow{6}{*}{ UGD } & \multirow{6}{*}{ Dokter umum } & Anamnesa & 3 menit \\
\hline & & Pemeriksaan fisik & 5 menit \\
\hline & & Melakukan tindakan kegawat daruratan & 10 menit \\
\hline & & Membuat catatan medis \& menulis resep & 2 menit \\
\hline & & konsultasi & 2 menit \\
\hline & & Melakukan rujukan & 2 menit \\
\hline
\end{tabular}

Sumber: Data Primer, 2019

Tabel 3. Kegiatan Pokok Dokter Umum Rumah Sakit Umum Daerah Kabupaten Buton Utara

\begin{tabular}{|c|c|c|c|c|c|}
\hline $\begin{array}{l}\text { Unit } \\
\text { Kerja }\end{array}$ & $\begin{array}{l}\text { Kategori } \\
\text { SDM }\end{array}$ & Kegiatan Pokok & $\begin{array}{c}\text { Waktu } \\
\text { Kerja } \\
\text { Tersedia } \\
\text { (WKT) }\end{array}$ & $\begin{array}{c}\text { Rata- } \\
\text { Rata } \\
\text { Waktu }\end{array}$ & $\begin{array}{c}\text { Standar } \\
\text { Beban } \\
\text { Kerja }\end{array}$ \\
\hline \multirow{3}{*}{$\begin{array}{l}\text { Poli } \\
\text { Umum }\end{array}$} & \multirow{3}{*}{$\begin{array}{l}\text { Dokter } \\
\text { Umum }\end{array}$} & anamnesa penyakit & 90.000 & 5 menit & 18000 \\
\hline & & $\begin{array}{l}\text { pemeriksaan fisik dan atau pemeriksaan } \\
\text { penunjang (rujukan) }\end{array}$ & 90.000 & 5 menit & 18000 \\
\hline & & $\begin{array}{l}\text { penulisan resep dan memberikan } \\
\text { penyuluhan }\end{array}$ & 90.000 & 5 menit & 18000 \\
\hline \multirow{6}{*}{ UGD } & \multirow{6}{*}{$\begin{array}{l}\text { Dokter } \\
\text { umum }\end{array}$} & Anamnesa & 90.000 & 3 menit & 30000 \\
\hline & & Pemeriksaan fisik & 90.000 & 5 menit & 18000 \\
\hline & & Tindakan kegawatdaruratan & 90.000 & 10 menit & 9000 \\
\hline & & $\begin{array}{l}\text { Membuat catatan medis dan Menulis } \\
\text { Resep }\end{array}$ & 90.000 & 3 menit & 30000 \\
\hline & & konsultasi & 90.000 & 2 menit & 45000 \\
\hline & & Melakukan rujukan & 90.000 & 2 menit & 45000 \\
\hline
\end{tabular}

Sumber: Data Primer, 2019

Tabel 4. Standar Kelonggaran Dokter Umum Rumah Sakit Umum Daerah Kabupaten Buton

\begin{tabular}{ccccr}
\hline \multirow{2}{*}{$\begin{array}{c}\text { Kategori } \\
\text { SDM }\end{array}$} & Faktor kelonggaran & Frekuensi & Rata rata waktu & $\begin{array}{c}\text { Standar } \\
\text { kelonggaran }\end{array}$ \\
\hline \multirow{3}{*}{$\begin{array}{c}\text { Dokter } \\
\text { umum }\end{array}$} & Rapat Komite Medik & 2 jam/bulan & 1440 menit/thn & 0,016 \\
\cline { 2 - 5 } & Visit Pasien kelas I, II \& II & 15 menit/hari & 5475 menit/thn & 0,060 \\
\cline { 2 - 5 } & Pendidikan dan pelatihan & 4 hari/Tahun & 5760 menit/thn & 0,064 \\
\cline { 2 - 5 } Jumlah & Waktu pribadi & 20 menit/hari & 7300 menit/thn & 0,081 \\
\cline { 2 - 5 }
\end{tabular}

Sumber: Data Primer, 2019 
Tabel 5. Kebutuhan Dokter Umum di Rumah Sakit Umum Daerah Kabupaten Buton Utara

\begin{tabular}{|c|c|c|c|c|c|}
\hline $\begin{array}{l}\text { Unit } \\
\text { Kerja }\end{array}$ & Kegiatan Pokok & $\begin{array}{c}\text { Standar } \\
\text { Beban } \\
\text { Keria }\end{array}$ & $\begin{array}{c}\text { Standar } \\
\text { Kelonggar } \\
\text { an }\end{array}$ & $\begin{array}{c}\text { Kuantitas } \\
\text { Kegiatan } \\
\text { Pokok }\end{array}$ & KDU \\
\hline \multirow{3}{*}{$\begin{array}{l}\text { Poli } \\
\text { Umum }\end{array}$} & anamnesa penyakit & 18000 & 0,221 & 130 & 0,22 \\
\hline & $\begin{array}{l}\text { pemeriksaan fisik dan atau } \\
\text { pemeriksaan penunjang } \\
\text { (rujukan). }\end{array}$ & 18000 & 0,221 & 130 & 0,22 \\
\hline & $\begin{array}{l}\text { penulisan resep dan } \\
\text { memberikan penyuluhan }\end{array}$ & 18000 & 0,221 & 130 & 0,22 \\
\hline \multirow{6}{*}{ UGD } & Anamnesa & 45000 & 0,221 & 366 & 0,22 \\
\hline & Pemeriksaan fisik & 45000 & 0,221 & 366 & 0,22 \\
\hline & Tindakan kegawat daruratan & 45000 & 0,221 & 366 & 0,22 \\
\hline & $\begin{array}{l}\text { Membuat catatan medis dan } \\
\text { Menulis Resep }\end{array}$ & 45000 & 0,221 & 366 & 0,22 \\
\hline & konsultasi & 45000 & 0,221 & 366 & 0,22 \\
\hline & Melakukan rujukan & 45000 & 0,221 & 366 & 0,22 \\
\hline Total & & & & & 1,6 \\
\hline
\end{tabular}

Sumber: Data Primer, 2019

Langkah keempat yaitu menentukan standar kelonggaran Dokter Umum Rumah Sakit Umum Daerah Kabupaten Buton Utara. Berdasarkan Tabel 4 menunjukkan bahwa standar kelonggaran dokter umum di RSUD Kabupaten Buton Utara sebesar 0,22. Artinya, setiap dokter umum mempunyai faktor kelonggaran sebesar 0,22 atau $22 \%$ dari total waktu kerja tersedia untuk melakukan kegiatan tambahan.

Langkah kelima yaitu menentukan kuantitas kegiatan pokok Dokter Umum di RSUD Buton Utara tahun. Berdasarkan Tabel 5 diketahui kuantitas kegiatan pokok yang akan digunakan untuk menghitung kebutuhan SDM pada unit kerja poli umum adalah sebesar 130 dan pada UGD sebesar 366.

Langkah keenam yaitu menghitung kebutuhan Dokter Umum di Rumah Sakit Umum Daerah Kabupaten Buton Utara. Berdasarkan hasil perhitungan kebutuhan dokter di RSUD Kabupaten Buton Utara menggunakan rumus WISN yaitu1,6 Dokter Umum.

\section{PEMBAHASAN}

Berdasarkan hasil penelitian pada Tabel 1 terhadap dokter umum di Rumah Sakit Umum Daerah Kabupaten Buton Utara diperoleh hari kerja tersedia bagi Dokter Umum di Poli Umum dan UGD adalah 244 hari/tahun dengan waktu kerja tersedia 1500 jam/tahun. Menurut Peraturan Menteri Keuangan Nomor 211 Tahun 2014 tentang hari dan jam kerja efektif di lingkungan Departemen Keuangan adalah 5 hari dan 42 jam perminggu, dengan allowance $25 \%$. $^{6}$ Sehingga jam kerja efektif perminggu adalah 32 jam atau 99.840 menit setahun. Selain itu, menurut Kepmenkes No. 81 Tahun 2004 waktu kerja tersedia untuk kategori Dokter Spesialis adalah 207 hari atau 1.656 jam pertahun atau 99.360 menit pertahun. Waktu kerja di atas tidak jauh bebeda dengan waktu 
kerja tersedia dokter umum di Poli Umum dan UGD RSUD Buton Utara yaitu dengan waktu kerja tersedia sebanyak 1.500 jam pertahun atau 90.000 menit pertahun. Waktu kerja tersedia di Poli Umum dan UGD RSUD Kabupaten Buton Utara masih jauh lebih besar dibandingkan penelitian Dewi yang menghitung waktu kerja dokter di RS Islam PKU Muhammadiyah sebesar 2.400 jam pertahun. ${ }^{7}$ Selain itu, pada penelitian Wangi, Agusdin, dan Nurmayanti didapatkan waktu kerja perawat di Ruang Rawat Inap RS Bhakti Yudha dalam setahun masih lebih besar dibanding waktu kerja tersedia di Poli Umum dan UGD RSUD Kabupaten Buton Utara dalam setahun yaitu 90.000 menit. $^{8}$ Hal ini dikarenakan perbedaan dalam pemberian hari kerja, hari cuti, perbedaan waktu pelatihan dan pendidikan, serta toleransi tidak masuk kerja. Dengan menggunakan pedoman teori ini, maka waktu kerja bagi dokter umum di Poli Umum dan UGD RSUD Kabupaten Buton Utara mendekati waktu kerja efektif namun belum mencapai tingkat waktu kerja efektif karena terdapat perbedaan perhitungan waktu kerja selama seminggu serta ketidakhadiran kerja yang ditolerir berdasarkan pada cuti tahunan, hari libur nasional serta waktu pelaksanaan pelatihan dan pendidikan.

Berdasarkan perhitungan waktu kerja dokter umum dalam seminggu di Poli Umum dan UGD RSUD Kabupaten Buton Utara, ratarata waktu kerja Dokter Umum yaitu 6 jam perhari dengan 6 hari kerja dalam seminggu. Hal ini tidak sejalan dengan ketentuan waktu kerja berdasarkan Undang-Undang nomor 13 Tahun 2003 tentang Ketenagakerjaan, bahwa untuk karyawan yang bekerja 6 hari dalam seminggu jam kerjanya yaitu 7 jam perhari, sedangkan untuk karyawan yang jam kerjanya 8 jam waktu kerjanya yaitu 5 hari dalam seminggu.

Menurut Gultom dan Sihotang diperolehnya unit kerja atau kategori SDM yang bertanggung jawab dalam menyelenggarakan kegiatan pelayanan perorangan, keluarga dan masyarakat di dalam dan luar rumah sakit merupakan fungsi dari menetapkan unit kerja dan kategori SDM dalam perhitungan WISN. Berdasarkan Tabel 2 Unit kerja yang diamati dan dihitung jumlah tenaganya dalam penelitian ini adalah Poli Umum dan UGD Rumah Rakit Umum Daerah Kabupaten Buton Utara sedangkan kategori SDMnya adalah semua Dokter umum yang bekerja di Rumah Rakit Umum Daerah Kabupaten Buton Utara. ${ }^{9}$

Kepmenkes RI Tahun 2004 menyatakan bahwa standar beban kerja adalah volume/kuantitas beban kerja selama 1 tahun per kategori SDM. Standar beban kerja untuk suatu kegiatan pokok disusun berdasarkan waktu yang dibutuhkan untuk menyelesaikannya (waktu rata-rata) dan waktu kerja tersedia yang dimiliki oleh Dokter Umum. Berdasarkan Tabel 3 Dokter Umum di Poli Umum memiliki standar beban kerja per tahun sebesar 1800 untuk melakukan pemeriksaan pasien. Artinya dokter umum dalam memeriksa pasien memerlukan waktu sebesar 1/18000 dari waktu kerja selama satu tahun di Poli Umum. Sementara itu Dokter Umum yang bertugas di UGD memiliki standar beban kerja sebesar 45000 
pemeriksaan pasien. Artinya Dokter Umum dalam memeriksa pasien memerlukan waktu sebesar 1/45000 dari waktu kerja selama setahun di UGD. Penelitian ini sejalan dengan penelitian Nengsih yang menyebutkan bahwa kategori dokter dan perawat memiliki beban kerja yang berbeda pada tiap unit kerja hal ini bukan berarti dokter dan perawat harus menjalankan setiap beban kerja yang ada, namun mereka juga melakukan berbagai kegiatan lain yang menyita jam kerja tersedia yang dimilikinya. ${ }^{10}$ Faktor yang mempengaruhi beban kerja tenaga kesehatan adalah kondisi jumlah pasien yang selalu berubah dan jumlah rata-rata jam yang dibutuhkan untuk memberikan pelayanan langsung pada pasien. ${ }^{11}$

Kepmenkes RI Tahun 2004 menyatakan bahwa, penyusunan standar kelonggaran tujuannya adalah diperolehnya faktor kelonggaran tiap kategori SDM meliputi jenis kegiatan dan kebutuhan waktu untuk menyelesaiakan suatu kegiatan yang tidak terkait langsung atau dipengaruhi tinggi rendahnya kualitas atau jumlah kegiatan pokok/pelayanan. Berdasarkan hasil penelitian pada Tabel 4 diketahui bahwa standar kelonggaran dokter umum di RSUD Kabupaten Buton Utara sebesar 0,22. Artinya, setiap dokter umum mempunyai faktor kelonggaran sebesar 0,22 atau dengan kata lain setiap Dokter Umum memerlukan 22\% dari total waktu kerja tersedia untuk melakukan kegiatan tambahan. Penelitian sebelumnya oleh Soesilowati dan Ratnasari diperoleh bahwa standar kelongaran Dokter Umum di Puskesmas Bantul sebesar 1,62 pertahun. ${ }^{12}$
Hal ini menunjukkan bahwa penelitian oleh Soesilowati \& Ratnasari memiliki standar kelonggaran lebih besar dibanding di Poli Umum dan UGD RSUD Kabupaten Buton Utara. Pada Tabel 4 kegiatan yang paling banyak menyita waktu adalah waktu pribadi yaitu sebanyak 0,081 atau $8,1 \%$ dari waktu kerja tersedia sedangkan kegiatan yang paling sedikit menyita waktu adalah rapat komite medik yaitu sebanyak 0,016 atau $1,6 \%$ dari waktu kerja tersedia. Hal ini sesuai dengan pendapat Rusli, Nusri, dan Farich bahwa faktor-faktor kelonggaran tersebut mengurangi waktu kerja tersedia. Kebalikan dengan beban kerja. Standar kelonggaran merupakan waktu untuk melakukan kegiatan lain di luar kegiatan pokok, artinya untuk mengerjakan faktor kelonggaran tersebut mengurangi waktu kerja tersedia yang ada. ${ }^{13}$

Rumah sakit sebagai fasilitas pelayanan kesehatan paripurna dalam pembangunan bidang kesehatan. Untuk dapat melihat kuantitas serta kualitas pelayanan kesehatan yang telah diberikan maka pengaruh sumber daya manusia merupakan titik keberhasilan suatu pelayanan. Oleh karena itu untuk dapat mengendalikan kuantitas dan kualitas pelayanan kesehatan dasar pada Rumah Sakit maka perlu dilakukan analisis beban kerja tenaga kesehatan di Rumah Sakit. Analisis beban kerja dengan menggunakan metode WISN pada penelitian ini ternyata mampu menjawab kebutuhan tenaga Dokter Umum. Berdasarkan hasil perhitungan kebutuhan dokter di RSUD Kabupaten Buton Utara menggunakan rumus WISN yaitu1,6 Dokter Umum. Berdasarkan aturan pembualatan yang 
diberikan oleh pedoman perlengkapan kerja WISN tenaga jika hasil perhitungan 1.1 dibulatkan kebawah menjadi 1 dan $>1,1-1,9$ dibulatkan keatas menjadi 2. Oleh karena itu jika hasil perhitungan kebutuhann Dokter Umum di RSUD Kabupaten Buton Utara 1,6 maka dibulatkan menjadi 2.

Kelebihan perhitungan tenaga kesehatan dengan analisis beban kerja adalah lebih fokus pada tenaga kesehatan serta uraian pekerjan yang ada pada unit kerja yang diteliti sehingga diperoleh hasil yang sesuai dengan beban kerja sesuai dengan uraian kerjanya. Dalam Keputusan menteri kesehatan No 81 tahun 2004 WISN merupakan metoda yang tepat dalam merencanakan tenaga kesehatan karena menghitung berapa banyak tenaga kesehatan (dari berbagai jenis) yang dibutuhkan di suatu fasilitas kesehatan berdasarkan beban kerja saat ini. WISN juga memungkinkan untuk meneliti berapa banyak petugas (dari berbagai jenis) yang akan dibutuhkan apabila beban kerja bertambah atau berkurang dimasa mendatang. Selain itu bahwa terdapat besarnya perbedaan tekanan beban kerja diantara para tenaga kesehatan yang dialami di berbagai fasilitas kesehatan. Tenaga kesehatan medis yang tersedia akan menentukan kemampuan pelayanan yang dapat diberikan oleh rumah sakit karena tenaga kesehatan merupakan kunci pelayanan. Jumlah tenaga kesehatan medis yang sesuai dan berkompeten memungkinkan rumah sakit memiliki kemampuan penanganan pelayanan yang paripurna. ${ }^{14}$

Oleh karena itu pemerintah daerah diharapkan untuk memastikan tersedianya sumber daya (sarana, prasarana, alat, tenaga kesehatan dan uang/biaya) yang cukup agar setiap warga negara dapat menggunakan haknya untuk memenuhi kebutuhan hidupnya tanpa hambatan atau halangan dari pihak manapun. Sampai ini saat secara umum RSUD Buton Utara masih membutuhkan tambahan tenaga Dokter Umum untuk memenuhi pelayanan kesehatan yang lebih paripurna kepada pasien RSUD Buton Utara. Penambahan tenaga Dokter Umum di RSUD Buton Utara masih dibutuhkan untuk mengurangi beban kerja Dokter Umum serta mampu berikan pelayanan yang paripurna bagi masyarakat Buton Utara karena tenaga Dokter Umum mempunyai peran penting dalam pelayanan di rumah sakit. Hal ini sejalan dengan penelitian lain yang menyebutkan bahwa tenaga kesehatan berperan sebagai perencana, penggerak dan sekaligus pelaksana pembangunan kesehatan, sehingga tanpa tersedianya tenaga dalam jumlah dan jenis yang sesuai serta berkompeten, maka akan mempengaruhi tercapainya pelayanan kesehatan yang optimal di masyarakat. ${ }^{15}$ Kebutuhan Dokter Umum di RSUD Buton Utara dibarengi dengan kesiapan sarana dan prasarana rumah sakit.

\section{KESIMPULAN DAN SARAN}

Penelitian ini menyimpulkan bahwa untuk memenuhi pelayanan kesehatan yang lebih paripurna kepada pasien Rumah Sakit Umum Daerah Buton Utara membutuhkan tambahan tenaga Dokter Umum sebanyak 2 orang. Diharapkan Rumah Sakit Umum 
Daerah Buton Utara untuk kedepannya untuk melakukan analisis lebih lanjut tentang beban kerja Dokter Umum untuk menangani kekurangan Dokter Umum di Rumah Sakit Umum Daerah Buton Utara. Diharapkan peran direktur rumah sakit sangatlah penting sebagai seorang pemimpin yang mempunyai tanggung jawab dan mampu memberikan perubahan dalam suatu organisasi demi perncapaian tujuan organisasi. Bagi peneliti selanjutnya diharapkan dapat menjadikan penelitian ini sebagai bahan masukan dan informasi untuk penelitian selanjutnya. Hasil penelitian ini dapat menjadi informasi tambahan bagi pemerintah daerah Buton Utara.

\section{UCAPAN TERIMA KASIH}

Ucapan terima kasih disampaikan kepada semua pihak yang telah membantu menyelesaikan penelitian ini dan ucapan terimakasih yang sebesar-besarnya penulis sampaikan pula pada pihak Yayasan Mandala Waluya Kendari yang telah memberikan kesempatan kepada kami dalam melaksanakan tridharma perguruan tinggi. Ucapan terima kasih kami sampaikan pula kepada pihak RSUD Kabupaten Buton Utara.

\section{DAFTAR PUSTAKA}

1. Kementerian Kesehatan, RI. Rencana Pengembangan Tenaga Kesehatan Tahun 2011-2025. Jakarta; 2011.

2. Kementerian Kesehatan. Profil Kesehatan Indonesia Tahun 2017. Jakarta; 2018.
3. Dinas kesehatan Sulawesi Tenggara. Data Profil Kesehatan Sulawesi Tenggara. Kendari; 2018.

4. Dinas kesehatan Buton Utara. Data Profil Rumah Sakit Tentang Rencana Kebutuhan Sumber Daya Manusia Kesehatan. Ereke; 2018.

5. Departemen kesehatan RI. Keputusan Menteri Kesehatan RI. Nomor 81/Menkes/SK/I/2004 Tentang Pedoman Penyusunan Perencanaan SDM Kesehatan di Tingkat Provinsi, Kabupaten/Kota Serta Rumah Sakit. Jakarta; 2004.

6. Menteri Kesehatan Republik Indonesia. Peraturan Menteri Keuangan Republik Indonesia Nomor 211 Tahun 2014. Jakarta; 2014.

7. Dewi N. Analisis Kebutuhan Tenaga Dokter Umum di Unit Gawat Darurat Rumah Sakit Islam PKU Muhammadiyah Tahun 2018. Kieraha Medical Journal. 2019;1(1):9-16.

8. Wangi NWS, Agusdin A, Nurmayanti S. Analisis Perencanaan Sumber Daya Manusia (SDM) Kesehatan Puskesmas Dengan Metode Workload Indicators of Staffing Needs (WISN) Di Kabupaten Lombok Barat. Jurnal Kedokteran. 2019;5(1):108-124.

9. Gultom SP, Sihotang A. Analisa Kebutuhan Tenaga Rekam Medis Berdasarkan Beban Kerja dengan Metode Wisn di Bagian Pendaftaran Rumah Sakit Umum Haji Medan Tahun 2018. Jurnal Ilmiah Perekam dan Informasi Kesehatan Imelda. 2019;4(1):524-532. 
10.Nengsih Y. Analisis Kebutuhan dan Kualifikasi Tenaga Dokter dan Perawat di Pelayanan Rawat Inap RSUD Bangkinang Kabupaten Kampar. Tesis: Program Studi Kajian Administrasi Rumah Sakit/ Fakultas Kesehatan Masyarakat/ Universitas Indonesia. Depok; 2014.

11. Asriati Y. Analisa Perencanaan Sumber Daya Manusia Dengan Metode Wisn Pada Petugas Rekam Medis Rumah Sakit X di Surakarta Jawa Tengah. Jurnal Manajemen Informasi dan Administrasi Kesehatan (JMIAK). 2019;2(02):12-18.

12. Soesilowati R, Ratnasari D. Analisis Peran Aktivitas Dokter Umum Dengan Metode Workload Indicator of Staffing Need (WISN) di Puskesmas Se-Kabupaten Bantul Yogyakarta. MEDISAINS. 2017;13(2):37-47.
13.Rusli Y, Nusri TM, Farich A. Analisis Beban Kerja Dokter dan Perawat di Poli Umum Puskesmas Kedaton Kota Bandar Lampung dengan Metode Workload Indicator Staff Needs (WISN). Jurnal Dunia Kesmas. 2013;2(1):12-18.

14.Akbar MI. Analysis of The Needs of General Practitioners In Public Health Centers Using Health Workload Method. Public Health of Indonesia. 2020;6(2):63-69.

15.Akbar MI, Alwi M, Thaha RM. Peta Kebutuhan Dokter Umum Berdasarkan Beban Kerja Untuk Mencapai Derajat Pelayanan Kesehatan yang Optimal di Puskesmas Se-Kabupaten Muna. JST Kesehatan. 2017;7(3):291-298. 